\title{
System Support Engineering Framework: A Tool to Achieve Strategy Transformation
}

\author{
Mohammed Saif Alsaidi, John P. T. Mo \\ School of Aerospace, Mechanical and Manufacturing Engineering, RMIT University, Melbourne, Australia \\ Email: mohammed.s.alsaidi@gmail.com
}

Received October 1, 2013; revised November 1, 2013; accepted November 8, 2013

Copyright (C) 2014 Mohammed Saif Alsaidi, John P. T. Mo. This is an open access article distributed under the Creative Commons Attribution License, which permits unrestricted use, distribution, and reproduction in any medium, provided the original work is properly cited. In accordance of the Creative Commons Attribution License all Copyrights (C) 2014 are reserved for SCIRP and the owner of the intellectual property Mohammed Saif Alsaidi, John P. T. Mo. All Copyright (C) 2014 are guarded by law and by SCIRP as a guardian.

\begin{abstract}
Modern refineries are complex, very high in value of production. They are expected to function for years to come, with ability to handle the changes in technology and feed quality. The aging of a refinery and continuous increases of vendors and contractors force the refinery's operation management to design a strategic approach which can capture these changes. Therefore, this paper explores and outlines the nature of the support system design for a refinery in order to comply with strategic transformation. The research work explores the operation support system from a range of perspectives, by interviewing managers from across the refinery organization. The factors contributing to complexity of a support system are described in the context presented, which clusters them into several key areas. It is proposed that SSE framework may then be used as analytical tool for managing and designing support system(s). The paper will conclude with discussion of potential application and strategic views of the framework. Also, it will designate the opportunities for future work.
\end{abstract}

\section{KEYWORDS}

System Support Engineering; Refinery; Performance; Complexity; Transformation; Support System Management

\section{Introduction}

Refinery stakeholders are demanding more value out of their asset by ensuring sustainability in operation. These include availability, readiness, extended operation and other value schemes. Literature shows that complex engineering industry is proposing the whole of systems approach to satisfy customer's needs. Support systems have to focus on links, interactions and the alignments of the elements [2]. As the refinery stakeholders intend (in some cases have) to outsource the support service and activities, the service provider will take significant part of the risk of sustaining capabilities of the refinery for the duration of the service contract [3-9]. In other words, the performance of the refinery will relate to or directly be affected by service of support provider(s). It is to the interest of the refinery owners (operator) that the refinery does perform as they wish. Hence, the relationship between the support service stakeholders should be clearly drawn and understood in regard to the implication and the nature of performing together to get the most out of the system.

The aging of a refinery and change in feed quality (crude oil) will lead to continuous increase on the number of contractors and processing units. This increase forces the refinery's operation management to design a strategy which can manage these changes. Furthermore, an accurate performance measurement and risk evaluation processes must be developed in alliance with the support system development.

\section{Industrial Example and Literature Review}

Using fresh information is essential to review our understanding of the current industrial practice. Learning process about system functionality always required particular level and depth of understanding of the system. Literature shows that several steps should be taking in order to realize 
thoughtful depth of understanding [10]. Moreover, Literature shows that because of its unique strengths, case study research is often used for developing new theories [11]. The external validity of multiple cases is not problematical issue or core requirement $[12,13]$ but it will strengthen the validation of the approach.

\subsection{Data Collection}

Literature shows that collecting conscious-based data through self-reporting is not good enough to succeed high accuracy information [14]. Therefore, an interpretation from people involved in the studied system to describe their professional understanding and thinking is hailed. This will inject the collected data with some sort of predictive validity to reasonable extent. The validation and revision of the outcomes was built on two main general strategies. Firstly, the critical feedback routes were highlighted and rated in order to capture and evaluate important results. Literature suggests that it could be useful if a researcher orders them based on the importance of each feedback route which could be difficult in this case. Instead the number and size of inputs and outputs of each route was considered to be the importance indicator. The second strategy is to analyse outcomes of the complexity. Using cause map as a step toward system dynamic mod- elling [15]. Such Cause maps will highlights the responds communication routes of real-life complex practice in the studied support systems (Figure 1).

The targeted benefits of industrial data collection are:

- An extension of the development technique of exiting support systems assessment in the industry by more explicitly treating their sustainability with the performance sustainability.

- Validation of the sufficiency of measurement tools for establishing roles and responsibilities for performance comprising a variety of enterprises and applications.

- Documentation of the realities of the world of professional practice regarding large and complex systems.

- Determination of the validity of the assumption employed by current systems engineering and performance standards.

- Guidance based on established practices on how to consolidate the system support functions responsible for supporting the performance. All in parallel of our expansion of understanding the roles and responsibilities of the performance charged with overseeing and ensuring the success of support system engineering and integration at the system level.

- Introduce recommendation of further studies and activities.

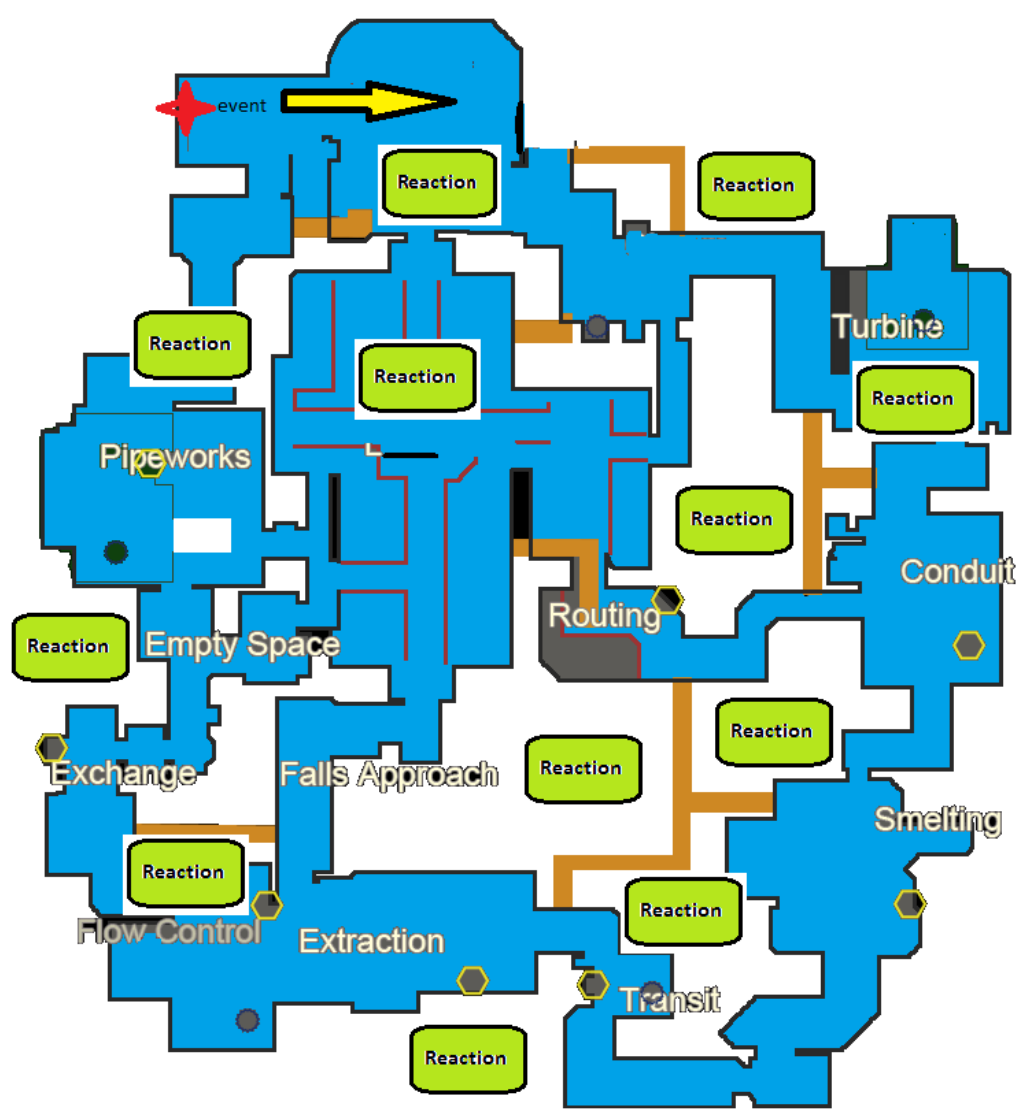

Figure 1. A generic cause map (event-reaction) for the studied refinery. 


\subsection{The Case Studied Refinery}

The Refining process is simply producing petroleum products and by-products by treating Crude Oil $[16,17]$ through three key processes: Distillation, Conversion and Cleanup (Figure 2). The Clean-up process is mainly removal of sulphur.

Sohar refinery is owned and operated by Oman Oil Refineries and Petroleum Industries Company (ORPIC) Figure 3. ORPIC Created from the integration of three companies [18]:
1) Oman Refineries and Petrochemicals Company LLC (ORPC);

2) Aromatics Oman LLC (AOL);

3) Oman Polypropylene (OPP).

ORPIC is one of Oman's largest companies and is one of the rapidly growing businesses in the Middle East's oil industry. It employs more than 1600 employees [19]. Sohar refinery is a combination of three major complexes:

1) On-Site Process Units

Units where all chemical reaction occurs

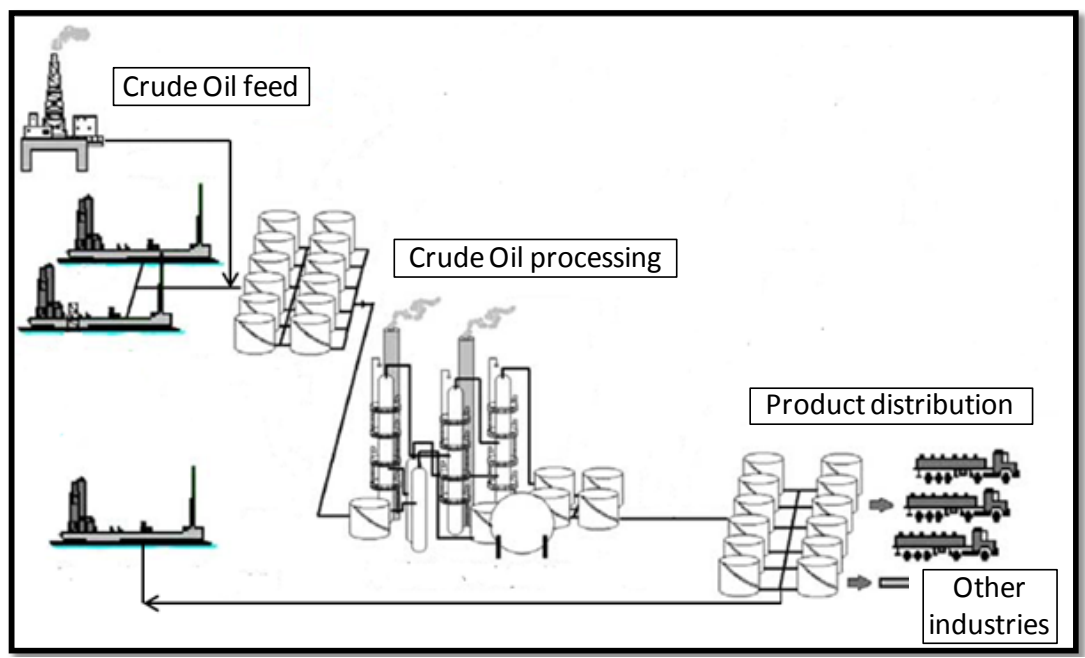

Figure 2. A general layout of a refinery.

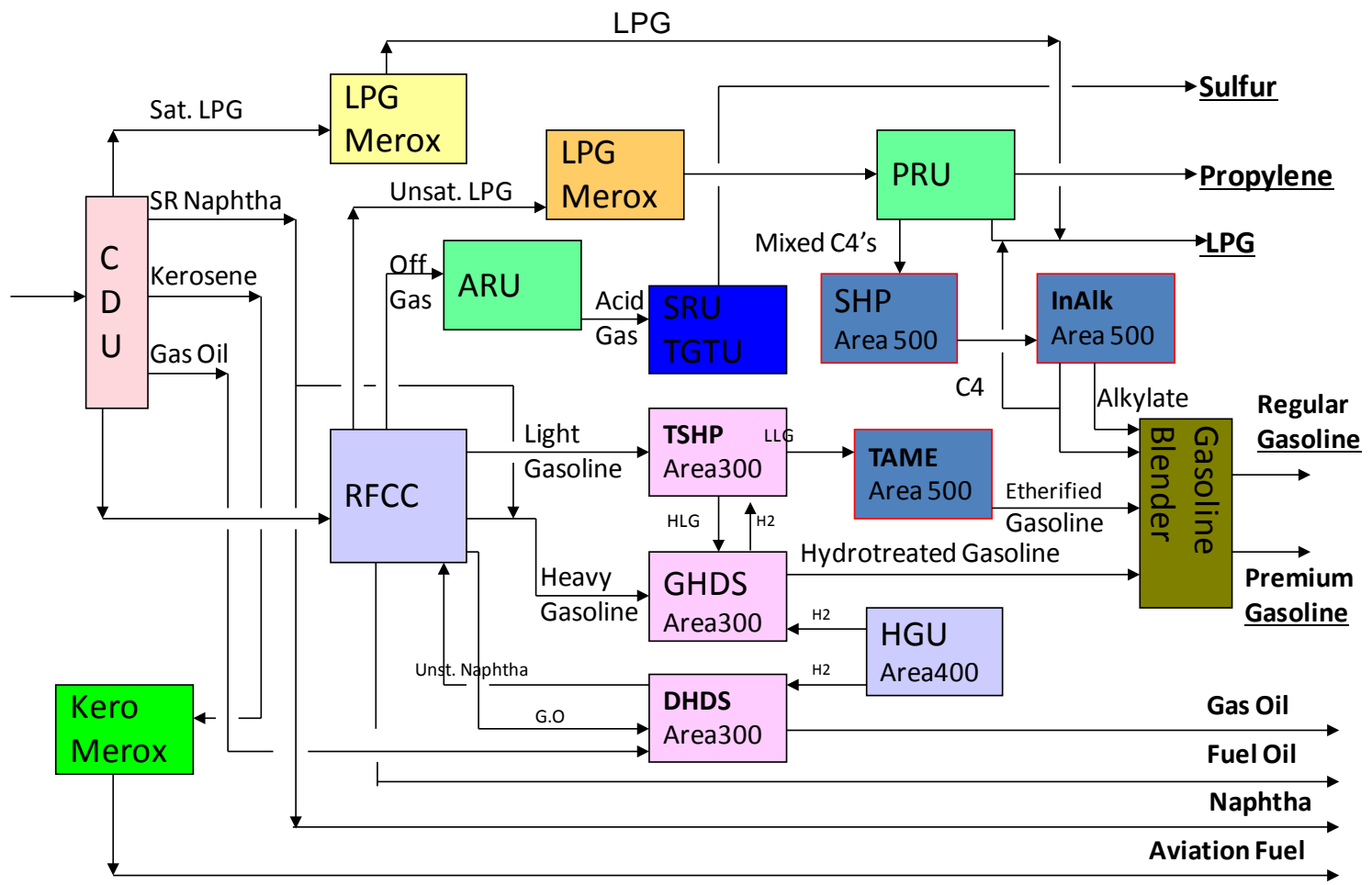

Figure 3. Overall process flow diagram for Sohar refinery. 
2) Utilities Facilities

- Power Plant, Electricity Receiving and Distribution System.

- Sea Water Intake Station

- Water system.

- Steam and Condensate system.

- Fuel Gas and Natural Gas System.

- Instrument Air and Plant Air system.

- Nitrogen System.

- Chemicals Preparation and Injection Facilities

3) Offsite Facilities [20]

- Feedstock \& Slops Tankage

- Product Tankage

- Marine Loading

- Truck Loading

- Waste Water Treating System

- Sulfur Granulation

- Bagging System

- Others

Sohar refinery is the heart of other chemical industries complexes in the Sohar port site, where it is the main supplier of their raw petrochemical materials. Hence, Sohar operative performance is significantly critical. In order to meet functional demand by the end users, the capability and efficiency of the system should keep increasing [21]. As a result of that, the management of the Sohar refinery needs to measure the performance of the support system to insure operations meets the demands. Performance measurements depend on good operation support data that is analyzed with sound methods and be translated into information and knowledge allowing decisions to take place.

To identify what parameters to measure, it is needed to first understand what to change to improve performance and subsequently, identify what are the measuring parameters.

After an investigation, data analysis and staff interviews, the main challenges were:

- People working behavior and culture understanding and training within organization.

- Process and system integration and harmonization as whole coherent systemic approach.
- Maintaining ongoing performance sustainability and improvement.

Based on the mentioned challenges, the refinery management agreed to site an improvement target (see Figure 4).

This supports the indication of a need to develop a structure(s) that practitioners in the refinery can use to help in support system design for operating refinery as a long-term service that maintains optimized performance and achieves the best return on investments. This structure should integrate industry domain knowledge to create and deliver a specific support solution for in-service refinery, as the circumstance requires.

Classical techniques in refinery management involve performance monitoring, process control and fault diagnosis techniques that aim to determine the limit of the unit's service life. Theoretically, replacement should be made at the time when the unit facility is about to fail so that the full service value of the unit can be utilized. However, this is not possible as modern petrochemical processing systems [22] are of increasing complexity and sophistication. Many other factors are governing the operations of the refinery. Most of these factors such as opportunity costs or lost customers are difficult to quantify and measure. Decisions such as asset replacement, upgrade or system overhaul and strategy transformation are in many respects equivalent to a major investment, which is risk sensitive. Therefore, solution centered proposition is needed in order to safely conduct transformation. Whither this transformation is technical or managerial.

\subsection{Basic Concepts and Literature Review}

Recent literatures showing that organizations and business leaders are always looking for new strategies which will allow stable transformation for better operation and increase investment return, and in some cases learn from the virtuous practitioners [23]. This comes with many challenges [24] especially if this changes the whole nature (model or strategy et al.) of an organization. This motivates the research stream to suggest varies strategies

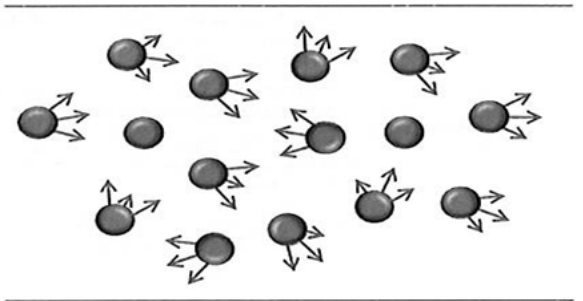

Independent elemental good performance approach

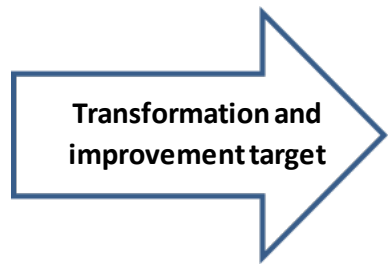

Transformation and

(1)

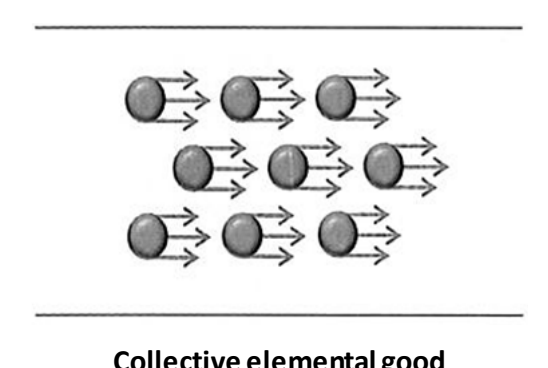

Collective elemental good performance approach

Figure 4. Management view of transforming operation support system. 
and tools in order to outline the rules of safer and more successful transformation, whichever this transformation is technological-driven [25] or as quality-driven response [26] and in some cases both. As a rule of thumb, organisations will be usually looking to reposition themselves and enhance the capability of operation systems for sustainable development. This generally is done through sustainable operation and innovation in some cases. Luckily, literature also suggested approaches to guide firms to be sustainably innovative [27].

\section{Concepts of System Support Engineering (SSE)}

It is proposed that system support concept could be a guide in providing a systematic modeling approach [28]. Therefore, a proposition was made to apply the generic framework of system supports engineering on designing operation system support of the refinery.

SSE concept involves the integration of service and system engineering to design support system. It incorporates a core knowledge base, drawing upon principles derived from a wide range of business and engineering disciplines. SSE is "solution centered", delivering output solutions which are a mix of service and product. Service is a dynamic and complex activity. In all services, irrespective of industry sectors or types of customers, services are co-produced with and truly involving consumers. In support system, service engineering and system engineering are used together as critical knowledge agents to guide the solution design. Service engineering emphasizes customization of solution designs to meet service needs, while system engineering accentuates technical performance of the solution. "Service and Support" is a strategic business model. The customer/supplier relationship is different from those of transactional service offerings where interactions are limited mainly to episodic experiences. In this model, the interactions with the customer are enduring, like the systems they support, and a support system seeks to cement a constructive long term customer relationship. To simplify this process, a generic framework of SSE was drawn by employing a empirical research [29].

SSE framework consists of 3 elements (People, Process and Product) in an operation environment structured in three levels (Execution, Management and Enterprise). The SSE framework model called 3PE model (Figure 5) was verified through multiple industrial visits and professionals contribution during data collection process. The SSE framework was able to outline the relation between the elements of system support.

The system support engineering model could systemically empower the application and implementation of ORPIC practical modern strategies. Though clearly indi- cates the type, the level of details, interaction elements and the operational environment. As ORPIC is intending to:

1) Higher highly skilled, trained and experienced employees whom have the ability to respond to the pressure of change. Moreover to keep up with dynamicity of the system and in some cases the uncertainty. Basically be able to use the available information to deal with what the day could though on them. This requires that the employee should clearly understand how the system work, interact and information flow routes and format.

2) Adopt experience and knowledge sharing systems and exercises.

3) Increase the rule of cooperation to the extent of partnership in some cases with its main stakeholder especially licensers and contractors. This basically aims to increase the focus and operation, especially of the organization. This could positively reflect on the quality of the performance. Moreover, to cut off or minimize cost by introduce saving on some activities. And strategically to get continuance feedback and suggestions form the key stakeholders and keep the gates open for extra business opportunities. This requires a clear understanding of interaction and communication roots, methods and format. Also it requires a clear identification of each party obligations, responsibilities and expectations in case of an extraordinary event.

4) Adopt holistic systemic approach to support high performance and reduce the uncertainties.

The benefits of the system support engineering model in relation to ORPIC needs and strategies are:

a) The performance elements in the system are independently measurable.

b) The measures are meaningful to people who use them by capturing a dimension of their performance in a way that they can understand.

c) The measures are continually evaluated in reference to the organization short and long term goals.

d) The measurement method will depending on the measured element where the most suitable and accurate method will be performed on the element and then later on all the results will be collected together to have overall system performance analysis in order to measure the system overall performance.

This process may sound very lengthy but its effectiveness and the process will speed up as the practice continued.

In a case of contracting, the System support framework is used to identify and undertake relationship with each element. Inevitably, the planning process begins by identifying the requirements and the operation environment, and then, by simultaneously considering the requirements changes over time and contribution potential of customers. 


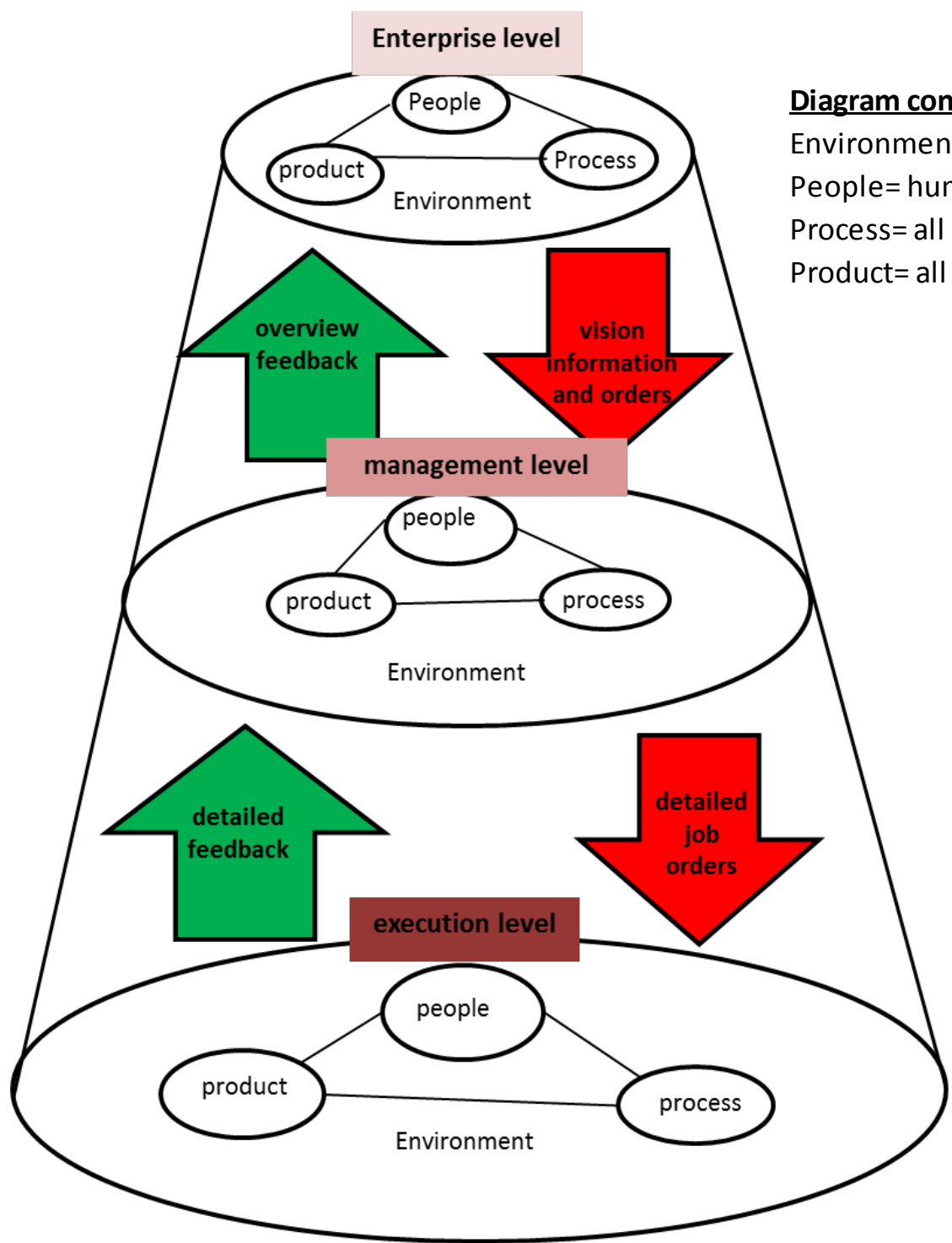

Figure 5. General vision of system support engineering framework (multi-level 3PE).

\section{Results and Discussion}

Literature says that usability of process models is powerfully associated with its simplicity of understanding [30]. The framework provided three increasingly detailed views or levels of abstraction from three different perspectives. It allows professionals to look at the same system from different perspectives. This creates a holistic view of system support. The framework in this regards helped to:

- Guide to set requirements identification procedure for the development process of an operational support system in the refinery.

- Provide an overview of the behavior vector of support system development process and clearly drawn relations between elements.

- Capture the strategic decisions, inventions and engi- neering trade-offs.

- Give an appreciation of Technical and commercial issues those are linkable from the maintenance and operation point of view.

- Be automated into the Enterprise Resource Planning (ERP) system.

\subsection{Outlining the Whole Process}

A standard development procedure was proposed as shown in Figure 6. This process schematic is completed by applying the philosophies of the SSE and detailed discussion with the professionals' in the refinery.

The overview process outlines the inputs and outputs flow during the developing processes of a proposed system. The process contains six main steps:

1) The initial proposal: where the project is proposed 


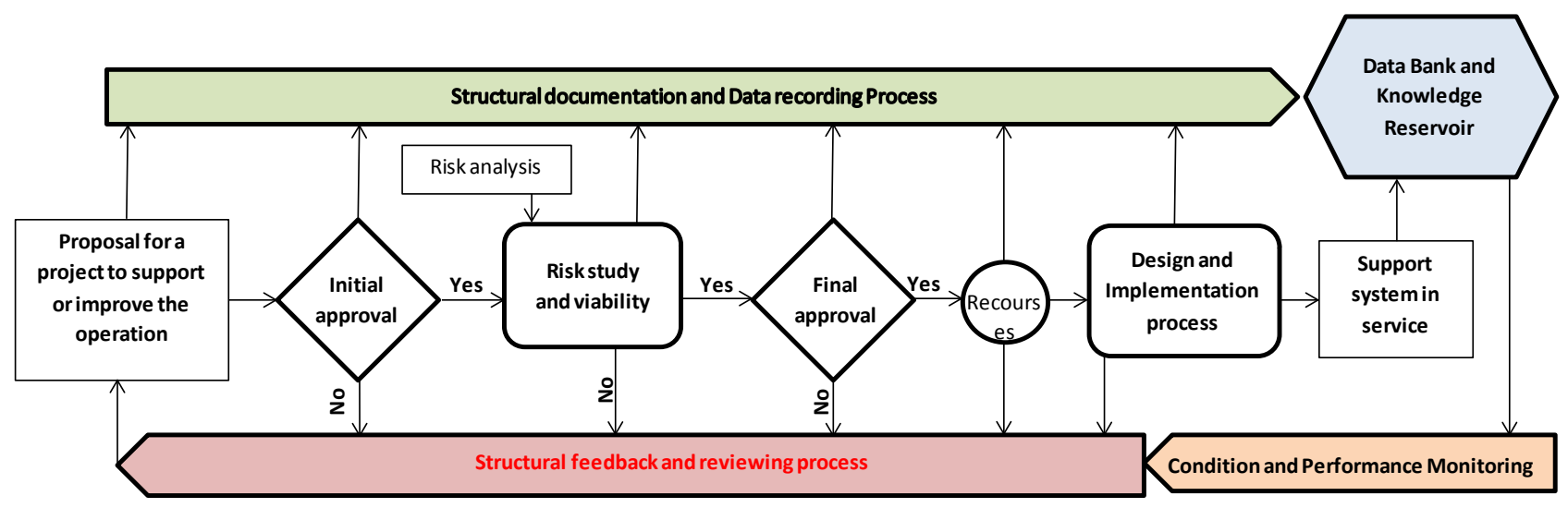

Figure 6. Overview of development process using the SSE concepts.

with the aim, main objectives, scope and expected out comes.

2) Initial approval; this stage is to get the resource approval to fund the further study and investigation.

3) Risk and viability study: this is to identify the risk associated with the project. The risk is usually divided into three main streams: cost, technical and occupational. The meaning of occupational is health, safety, environmental impact and legislations. The risk study is consulted by the outcomes of the detailed risk analysis process shown in Figure 6. The viability process is based on the adopted business model and the market study which is optimized combination of the current and forecasting market situation. Also, employing the methodologies of business transformation mentioned in the literature.

4) Final approval: this is the approval for the project to kick-off and assigning resources for the project.

5) Design and implementation: in this process the detailed design is finalized and implemented. This process is explained in more details later on and shown in Figure 7.

6) Support system in-service: this process is mainly to ensure that:

a) The operation and performance is sustainable.

b) The monitoring process and instruments are effective.

c) The data are recorded correctly in order to contribute and feed the Data bank Knowledge reservoir.

\subsection{Risk Study}

Uuncontrolled events are the supreme challenge could face any system designer or operator. This could happen in three main areas for the refinery: cost, technology and operation. According to the ISO 31000 (2009)/ISO Guide 73:2002, risk has been defined as the "effect of uncertainty on objectives". The analysis method or procedure is a key factor and a tool for system evaluation [31]. Consequently, a standard risk analysis procedure (shown in Figure 7) was developed to consult the risk study progression.

Risk tolerance will depend on the criticality of the unit or process that the support system is designed for. In fact all the mentioned categorizes of risk are interconnected to each other's and directly affecting each other's. Therefore they are analyzed in parallel. The risk analysis process is built into four main stages:

1) Risk Identification: is fed from detailed risk examines. These examines are categorized into three main streams:

a) Cost risk investigation: it has been found that price the refinery system is complex. As a result, the cost analysis would be a bottom-up approach to allow effective cost allocation when disintegrating systems, subsystems and elements to the appropriate level of inquisitiveness. This approach is delineated based on the SSE Framework. It should analyze:

$>$ The cost-effectiveness and efficiency.

$>$ Cost-utility.

$>$ Cost-benefit.

b) Technical risk investigation: Technical risk is a major factor to be considered in the acquisition of refinery capabilities. While the application of developmental technology offers potentially significantly enhanced capability over existing systems, it can also lead to excessive delays and cost blow-outs. Example of that, is delivering on specification product to consumer (offspec quality et al.) and work is not delivering the right operation, maintenance and support to sustain the profitability of the operation. The technical risk analysis is aiming:

$>$ To understand the origin and level of technical risk.

$>$ To check that the project strategy and resources are appropriate to the level and type of technical risks. Also, propose how the identified issues will be managed.

c) Occupational risk investigation: in the refinery case there are three main tributaries of occupational risk. These are safety, environment and regulations. 


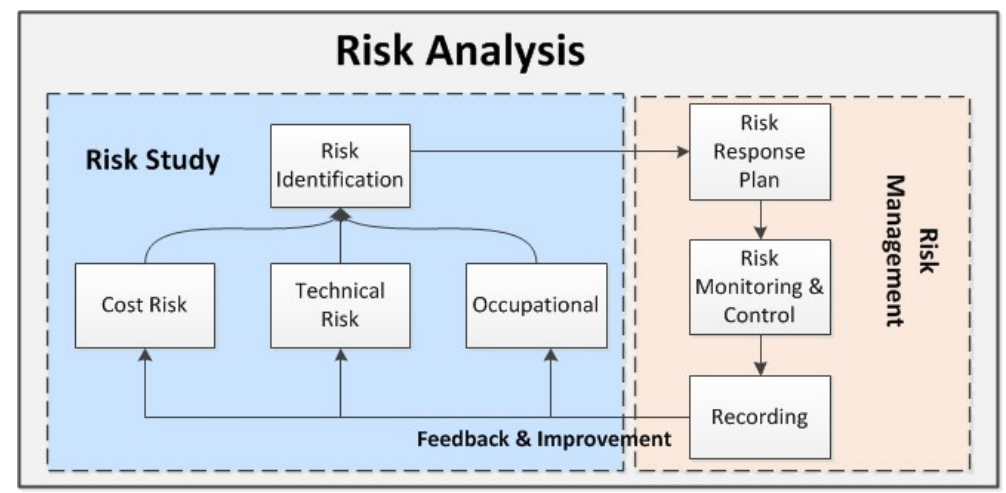

Figure 7. Standard risk analysis procedure.

2) Risk response plan: after identifying the risk from erstwhile process, the risk response plan is prepared. The reason why the risk response planning is an independent process from risk analysis because they have different objectives [32]. The aim of the risk response planning is to develop options and determine actions to enhance opportunities and minimize threats to system objectives. Also, it should assign responsibility to individuals or parties for each risk response. As an output of the plan, the plan should describe the types of incidents or crisis situations in which it will need to be used. It should outline the actions that need to be taken to limit the losses.

3) Risk monitoring and control: this process in general is aiming to Keep track of the identified risks and identify new risks arising during the development and the operation of support system. Usually there is more than one method of risk control for a particular problem [33]. In the SSE model is about the risk associated with the 3Ps' elements and how the surrounding environment (E) could contribute to that.

Recording: the recording process should comply with the overall recoding process stated previously.

\subsection{Design and Implementation Process}

The third stage was to develop a standard design and implementation process to fit into the development procedure of a support system, with consultation of the refinery professionals. Investigations indicate that the standard design and implementation method should:

- Organizes and covers all the requirements in order to avoid misperception and shortage and minimize reliance on expert judgments.

- Present the nature of the interaction and interface between the elements in the support system where it is clearly identified and gives a clear meaning to all participants.

- Give an allocation for objectives and outcomes which are clearly defined and established. This will be structured to be used for the decision-making process.
Some of the key elements are the order information and feedback information, which are grouped in the same classification in each level (enterprise, management and process, et al.) with different detailed depths. This will provide an easier allocation mechanism for future reference. All the information should be structured in order to provide the basic building unit for the design and implementation method. Figure 8 shows the design and implementation method.

The standard design and implementation method contains the following:

1) Proposal approval process: proposal approval is basically an assessment process. Literature stated that any assessment process which could affect a performance should refer to a reference model [34]. In order for a proposal to be approved, the proposer should include a clear project scope or instruction. Also, they should assign a qualified team to lead and manage the project. Both project scope and team information should follow the information guide line mentioned in the table shown in Figure 8.

2) After the project gets the initial approval, the first phase of the project is started. This stage is considered to be the theoretical preparation or framing of the project which should give an answer of what are the requirements and charges as well as the available possibilities. In order to do so, phase one contains three sub-activities. These sub-activities are interrelated and conducted in parallel for time saving:

a) As the project is habitually driven by the refinery industrial needs, a full understanding of the current state is required. This understanding often achieved through Context-specific study. Context-specific study is addressing the required objectives by the involved stakeholders (users, vendors, etc.) [35]. SSE model is assisting this Context-specific study and guides comprehending the available solutions and options.

b) Theoretical revision shows that action planning is core step in developing any system and it is built on plan selection and plan evaluation [36]. This enables consid- 


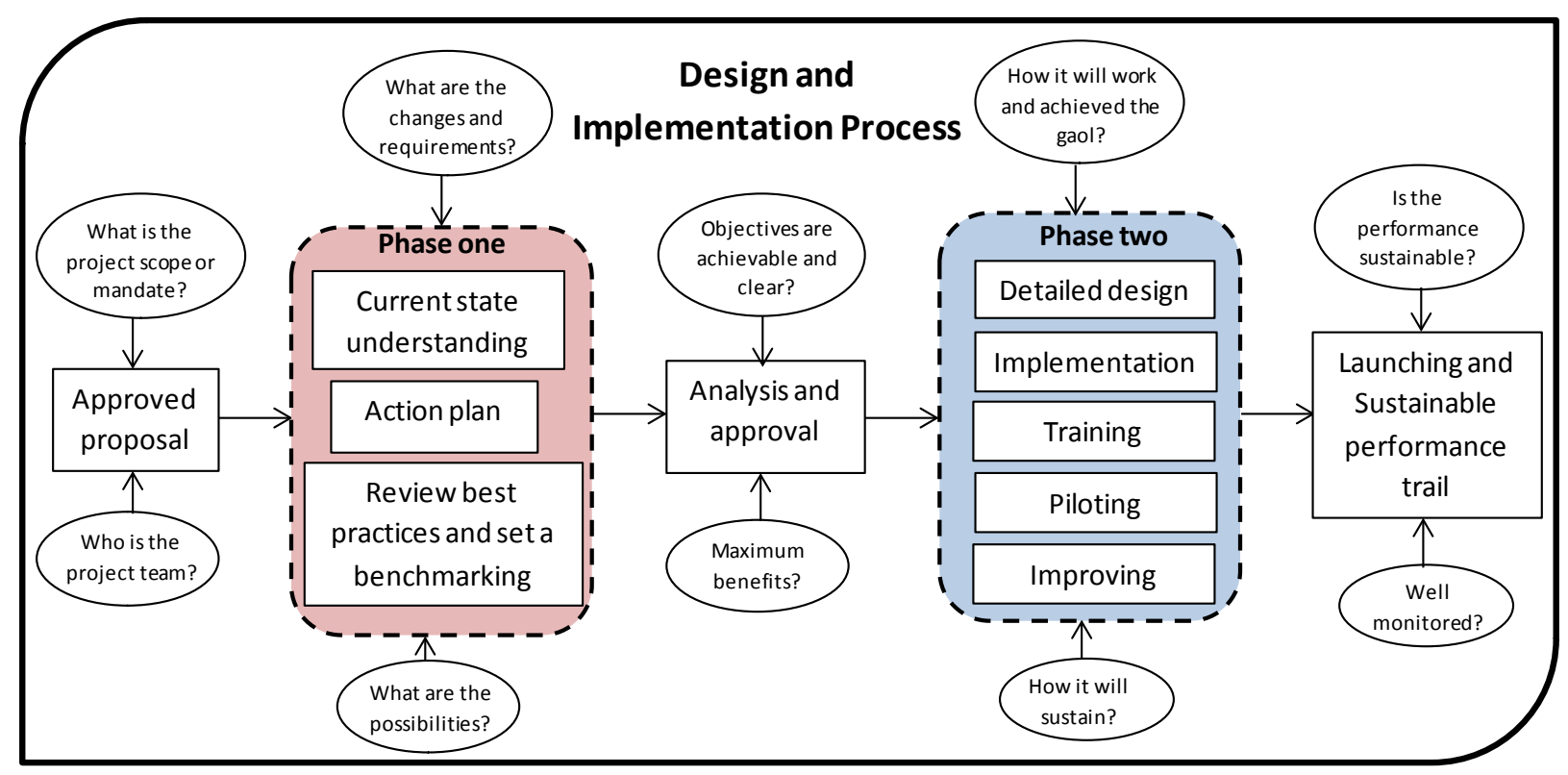

Figure 8. Standard design and implementation method.

eration of how emerging technology may change the way engineering systems operate and change over time [37]. Even resent literature reached the conclusion the action planning should be built on specified Architecture to accomplish healthier outcomes [38]. Consequently the action plan is erected with acquiescence of SSE model.

c) Benchmarking proved to be efficacious strategy employed by other industries [39-43]. Moreover, literature showed that reviewing and evaluating the best practices is an influential tool to gain knowledge for new progress. Published studies showed examples of modern industries improved though implementing benchmarking strategy [44]. Hence the benchmarking was included in phase one. This exercise is aiming to give the practitioners in the refinery the knowledge required for the new proposed system. SSE was used for better benchmarking process employed by the practitioners during the study in this paper.

3) The analysis for the final approval was built to mainly answer to questions which are uppermost for decision making in the industry. The first question is about whether the objectives are clear and most importantly achievable within the budget and time frames. The second question is about measuring if what is proposed to the maximum possible benefits.

4) Phase two is about moving ahead on implementing the permitted proposal. The impression of phase two is to answer two key questions. The first question is about the details of how the approved proposal will work and attained the established targets. The most importantly is answering the second question which is about how to sustain the implemented solution. The points out questions are retorted through performing the following sub- activities:

a) The detailed design is about building details and matching every single output to required input. This through engaging the principles of system engineering design codes [45] with reference to the SSE framework to identify the detailed principles of the design. There are moreover models available which could help to make you designing process more creative [46]. In some cases, some parts (particularly parts regarding human interaction) of the support system are designed for the refinery in order to provide transformative design solution. Then, will start with requirement engineering exercise to get the detailed requirement. Literatures showed examples of applying such strategy on implementing new system for different purposes [47-49]. After that the transformation of the design detailed conditions to design conclusions will take a place to suite the detailed task. These design conclusions should be built on knowledge-based engineering (KBE) methodology [50,51] which is available in house expertise and contracted consultancy bodies.

b) The implementation in this phase will be a combination of two main streams. The start-up stream is to magnify the details of the implementation plan. This exercise should not take long as it built on the already developed knowledge from the preceding stages but it is essential to uncover any implementation out of sight details and to review the former activities. The implementation plan is mainly about the detailed methodology and planning or resources distribution for constructing the approved system. The second stream is simply performing the construction.

c) Training usually starts immediately after the project 
is approved. Training plans is already prepared in phase one but the details of the training programs are fully completed at the early days of phase two. The reason for that is that the training is divided into four programs: design training, training for implementation, training for operation and training to maintain and sustain the system.

d) Piloting is basically sunning a safe to fail trails in the new system revile any hidden problems. And test the ability and the capability of the new system.

e) Improving process is a nature result of any finding and discoveries for the piloting activity.

5) Launching and sustainable performance is about monitoring the performance. This will aim to answer two main questions. First question is about how sustainable is the performance of the system. The second question about how effective is the monitoring of the system.

\subsection{Information Exchange}

The next step is to develop information structure format which will travel and carry information through the development process of a support system. Several versions of information structuring methods were developed and tested against the proposed or planned projects in the refinery. The table in Figure 9 showed the best results so far and was implemented by practitioners in a project.
In the Figure 9, litters are referring to process and procedures for confidentiality reasons they cannot be explained. The numbering is basically to indicate the order of executing. One means should be done at the start of the activities mentioned in the column and so on until all activities in the column are performed. Then start the activities in the next column. The direction is from left to right. The streams of information exchange are:

1) Classification (highlighted green color).

2) Authorization (highlighted red color).

3) Study, design and planning (highlighted in blue color).

4) Implementation planning, management and execution (highlighted in blue color).

5) Inspection and evaluation (highlighted in blue color).

6) Referencing and knowledge reservoir storage (highlighted in blue color).

This will give a unified information arrangement construction where the information category is defined to avoid misunderstanding or confusion.

The data can be uploaded and integrated to the Enterprise Resource Planning (ERP) which is SAP in the Sohar refinery case. Where the information could be made available to a variety of users and controlled by classified accesses gates.

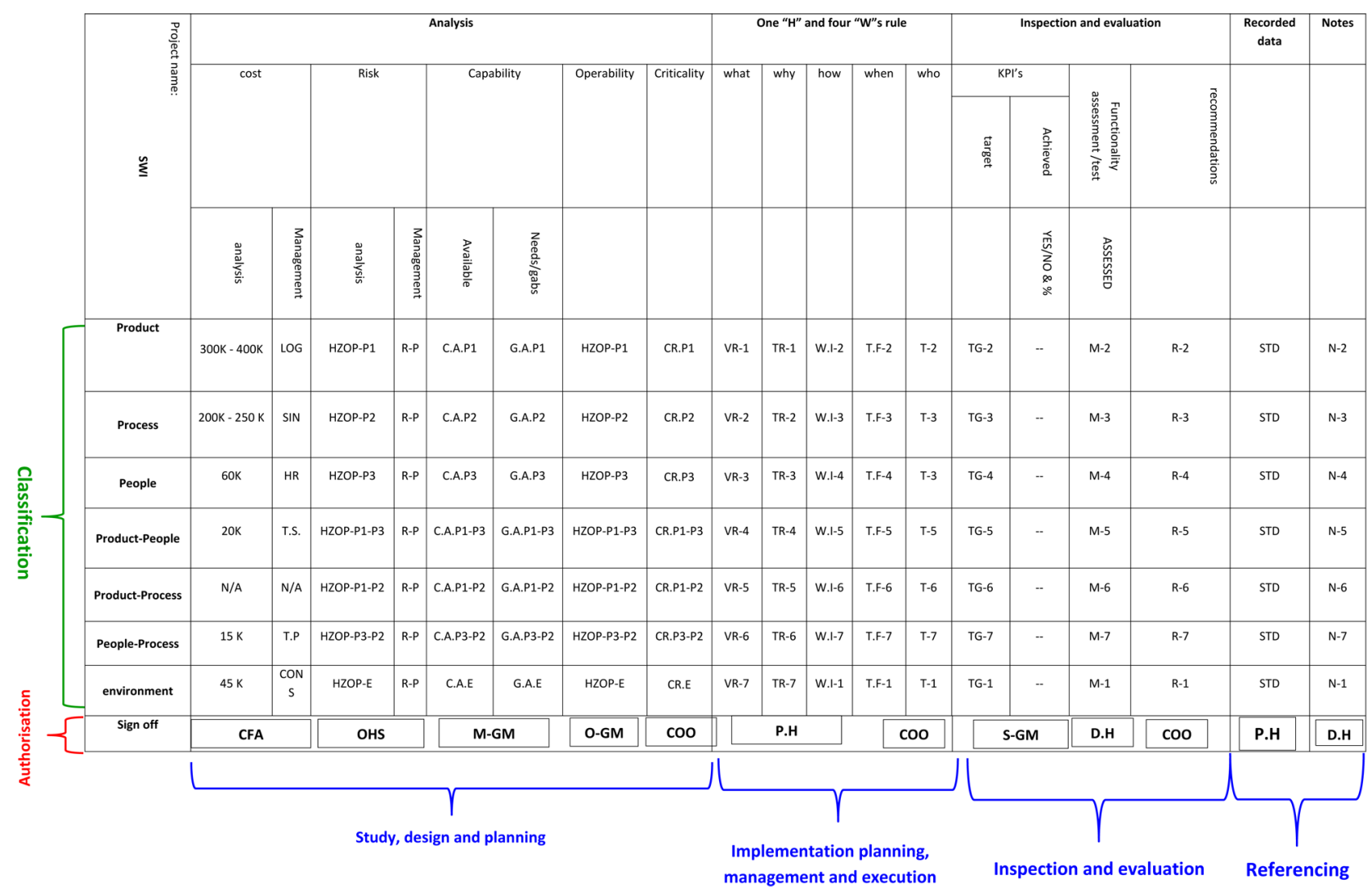

Figure 9. And overview for standard information exchange structure. 


\section{Conclusion and Future Research}

This paper explored and outlined the nature of the support system design for a refinery in order to comply with strategy transformation. The research work explored the operation support system from a range of perspectives, by interviewing managers from across the refinery organization. The factors contributing to complexity of a support system are described in the context presented; which clusters them into several key areas. It is proposed that SSE framework may then be used as analytical tool for managing and designing support system(s). The paper will conclude with discussion of potential application and strategic views of the framework. There are potential for future research work presented in several areas. Further investigation is suggested for future research:

- Further investigation on improving the documentation detailed process and efficient building of knowledge reservoir.

- The information exchange system needs to be further investigated from the IT point of view. Where the investigation will concentrate on the technical requirements to develop the logic gate and automatic information system software which will control and filter the flow of information.

- The performance indicators (KPI's) need to be further investigated to improve the details and accuracy of measurement of the developed procedures and this KPI's are integrated to the ERP system.

\section{Acknowledgements}

The authors acknowledge and deeply express their appreciation for the support provided by Oman Oil Refineries and Petroleum Industries Company (ORPIC). Especially Mr. Raphael De Loenen the COO of ORPIC and the rest of staff.

\section{REFERENCES}

[1] U. R. Chaudhuri, "Plant Management and Economics,” In: U. R. Chaudhuri, Ed., Fundamentals of Petroleum and Petrochemical Engineering, CRC Press, Boca Raton 2010, pp. 343-373. http://dx.doi.org/10.1201/b10486-16

[2] M. S. Al Saidi, J. P. T. Mo and A. S. B. Tam, "Systemic Approach to Strategic Performance Sustainability and Evaluation," PMA 2012 Conference-From Strategy to Delivery, Cambridge, 2012.

[3] Y. Li, X. Wang and T. M. Adams, "Ride Service Outsourcing for Profit Maximization," Transportation Research Part E: Logistics and Transportation Review, Vol. 45, No. 1, 2009, pp. 138-148.

http://dx.doi.org/10.1016/j.tre.2008.02.006

[4] B. Feng, Z.-P. Fan and Y. Li, "A Decision Method for Supplier Selection in Multi-Service Outsourcing,” International Journal of Production Economics, Vol. 132, No.
2, 2011, pp. 240-250

http://dx.doi.org/10.1016/j.ijpe.2011.04.014

[5] S. Lin and A. C. Ma, "Outsourcing and Productivity: Evidence from Korean Data," Journal of Asian Economics, Vol. 23, No. 1, 2012, pp. 39-49. http://dx.doi.org/10.1016/j.asieco.2011.11.005

[6] H. Görg and A. Hanley, "Services Outsourcing and Innovation: An Empirical Investigation,” Economic Inquiry, Vol. 49, No. 2, 2011, pp. 321-333. http://dx.doi.org/10.1111/j.1465-7295.2010.00299.x

[7] O. F. Bustinza, D. Arias-Aranda and L. Gutierrez-Gutierrez, "Outsourcing, Competitive Capabilities and Performance: An Empirical Study in Service Firms,” International Journal of Production Economics, Vol. 126, No. 2, 2010, pp. 276-288.

http://dx.doi.org/10.1016/j.ijpe.2010.03.023

[8] H.-H. Lee, E. J. Pinker and R. A. Shumsky, "Outsourcing a Two-Level Service Process,” Management Science, Vol. 58, No. 8, 2012, pp. 1569-1584.

http://dx.doi.org/10.1287/mnsc.1110.1503

[9] S. Cai, K. Ci and B. Zou, "Producer Services Outsourcing Risk Control Based on Outsourcing Contract Design: Industrial Engineering Perspective,” Systems Engineering Procedia, Vol. 2, 2011, pp. 308-315. http://dx.doi.org/10.1016/j.sepro.2011.10.043

[10] Y. Correa and C. Keating, “An Approach to Model Formulation for Systems of Systems," IEEE International Conference on Systems, Man and Cybernetics, 2003.

[11] M. Gibbert and W. Ruigrok, "The 'What' and 'How' of Case Study Rigor: Three Strategies Based on Published Work," Organizational Research Methods, Vol. 13, No. 4, 2010, pp. 710-737. http://dx.doi.org/10.1177/1094428109351319

[12] R. K. Yin, “Case Study Methods,” In: H. Cooper, et al., Ed., APA Handbook of Research Methods in Psychology, Vol. 2: Research Designs: Quantitative, Qualitative, Neuropsychological, and Biological, American Psychological Association, Washington DC, 2012, pp. 141-155.

[13] M. Woolcock, "Using Case Studies to Explore the External Validity of 'Complex' Development Interventions," Evaluation, Vol. 19, No. 3, 2013, pp. 229-248. http://dx.doi.org/10.1177/1356389013495210

[14] P. Runeson and M. Höst, "Guidelines for Conducting and Reporting Case Study Research in Software Engineering," Empirical Software Engineering, Vol. 14, No. 2, 2009, pp. 131-164. http://dx.doi.org/10.1007/s10664-008-9102-8

[15] A. G. Woodside, "Bridging the Chasm between Survey and Case Study Research: Research Methods for Achieving Generalization, Accuracy, and Complexity,” Industrial Marketing Management, Vol. 39, No. 1, 2010, pp. 64-75. http://dx.doi.org/10.1016/j.indmarman.2009.03.017

[16] M. A. Fahim, T. A. Alsahhaf and A. Elkilani, "Fundamentals of Petroleum Refining," Chemical, Petrochemical \& Process, 2010, pp. 1-487.

[17] U. R. Chaudhuri, “Crude Petroleum Oil,” In: U. R. Chaudhuri, Ed., Fundamentals of Petroleum and Petrochemical Engineering, CRC Press, Boca Raton, 2010, pp. 1-23. 
http://dx.doi.org/10.1016/j.indmarman.2009.03.017

[18] Company, O.O.R.a.P.I., “Our Company,” 2013. http://orpic.om/page/details/key/our-company\#rights

[19] (GPCA), G.P.a.C.A. ORPIC, 2013. http://gpca.org.ae/congulf/blog/orpic

[20] U. R. Chaudhuri, "Offsite Facilities, Power and Utilities,” In: U. R. Chaudhuri, Ed., Fundamentals of Petroleum and Petrochemical Engineering, CRC Press, Boca Raton, 2010, pp. 131-150. http://dx.doi.org/10.1201/b10486-7

[21] J. Mo, "Services and Support Supply Chain Design for Complex Engineering Systems,” In: P. Li, Ed., Supply Chain Management, InTech, Rijeka, 2011, pp. 515-532.

[22] U. R. Chaudhuri, "Instrumentation and Control in a Refinery,” In: U. R. Chaudhuri, Ed., Fundamentals of Petroleum and Petrochemical Engineering, CRC Press, Boca Raton, 2010, pp. 297-324. http://dx.doi.org/10.1201/b10486-14

[23] M. Kodama, "Boundaries Innovation and Knowledge Integration in the Japanese Firm," Long Range Planning, Vol. 42, No. 4, 2009, pp. 463-494. http://dx.doi.org/10.1016/j.lrp.2009.08.001

[24] V. Martinez, et al., "Challenges in Transforming Manufacturing Organisations into Product-Service Providers," Journal of Manufacturing Technology Management, Vol. 21, No. 4, 2010, pp. 449-469. http://dx.doi.org/10.1108/17410381011046571

[25] T. Shibata, "Managing Parallel Development towards Technological Transitions," International Journal of Technology Management, Vol. 60, No. 3, 2012, pp. 281-301. http://dx.doi.org/10.1504/IJTM.2012.049427

[26] C.-H. Kuei and M. H. Lu, "Integrating Quality Management Principles into Sustainability Management," Total Quality Management \& Business Excellence, Vol. 24, No. 1-2, 2012, pp. 62-78. http://dx.doi.org/10.1080/14783363.2012.669536

[27] I. Nonaka, et al., "Dynamic Fractal Organizations for Promoting Knowledge-Based Transformation-A New Paradigm for Organizational Theory," European Management Journal, Vol. 32, No. 1, 2014, pp. 137-146.

[28] J. P. T. Mo, "System Support Engineering: The Foundation Knowledge for Performance Based Contracting," ICOMS2009, Sydney.

[29] M. S. Al Saidi and J. P. T. Mo, "An Empirical Approach to Model Formulation for System Support Engineering," International Journal of Engineering Business Management, Vol. 5, No. 11, 2013.

[30] J. Mendling, H. A. Reijers and W. M. P. van der Aalst, "Seven Process Modeling Guidelines (7PMG)," Information and Software Technology, Vol. 52, No. 2, 2010, pp. 127-136. http://dx.doi.org/10.1016/j.infsof.2009.08.004

[31] R. Lock, "Developing a Methodology to Support the Evolution of System of Systems Using Risk Analysis," Systems Engineering, Vol. 15, No. 1, 2012, pp. 62-73. http://dx.doi.org/10.1002/sys.20194

[32] F. Chao, F. Marle, M. Xie and E. Zio, “An Integrated Framework for Risk Response Planning under Resource Constraints in Large Engineering Projects,” IEEE Transactions on Engineering Management, Vol. 60, No. 3, 2013, pp. 627-639.

http://dx.doi.org/10.1109/TEM.2013.2242078

[33] Q. H. Zhang, “The Model Research on Risk Control,” In: The 19th International Conference on Industrial Engineering and Engineering Management, Springer, Berlin, 2013, pp. 653-659.

[34] F. Franceschini, M. Galetto and E. Turina, "Impact of Performance Indicators on Organisations: A Proposal for an Evaluation Model,” Production Planning \& Control, 2013, pp. 1-17. (ahead-of-print)

[35] P. Mohagheghi, W. Gilani, A. Stefanescu and M. A. Fernandez, "An Empirical Study of the State of the Practice and Acceptance of Model-Driven Engineering in Four Industrial Cases,” Empirical Software Engineering, Vol. 18, No. 1, 2013, pp. 89-116. http://dx.doi.org/10.1007/s10664-012-9196-x

[36] E. Bassett and V. Shandas, "Innovation and Climate Action Planning," Journal of the American Planning Association, Vol. 76, No. 4, 2010, pp. 435-450. http://dx.doi.org/10.1080/01944363.2010.509703

[37] D. L. Farber, "Understanding Engineering Systems Futures: Using Scenario Analysis and Planning to Develop Engineering Systems Leadership,” College of Engineering, Pennsylvania State University, Pennsylvania, 2011.

[38] B. Boehm, J. Lane, S. Koolmanojwong and R. Turner, "An Evidence-based Systems Engineering (SE) Data Item Description,” Procedia Computer Science, Vol. 16, 2013, pp. 898-907.

http://dx.doi.org/10.1016/j.procs.2013.01.094

[39] H. Shamma and S. Hassan, "Customer-Driven Benchmarking: A Strategic Approach toward a Sustainable Marketing Performance," Benchmarking: An International Journal, Vol. 20, No. 3, 2013, pp. 377-395.

[40] M. A. Neves, M. Totrov and R. Abagyan, "Docking and Scoring with ICM: The Benchmarking Results and Strategies for Improvement," Journal of Computer-Aided Molecular Design, Vol. 26, No. 6, 2012, pp. 675-686. http://dx.doi.org/10.1007/s10822-012-9547-0

[41] S. Iantorno, K. Gori, N. Goldman, M. Gil and C. Dessimoz, "Who Watches the Watchmen? An Appraisal of Benchmarks for Multiple Sequence Alignment,” 2012. arXiv: 1211.2160, preprint.

[42] A. Löytynoja, "Alignment Methods: Strategies, Challenges, Benchmarking, and Comparative Overview,” In: Evolutionary Genomics, Springer, Berlin, 2012, pp. 203-235. http://dx.doi.org/10.1007/978-1-61779-582-4_7

[43] O. James, "The Effectiveness of Benchmarking as an Organizational Transformation Strategy in Higher Education Institutions in South Africa," Proceedings of the International Conference on Education, Research and Innovation 2012, Madrid, 20-21 November 2012, pp. 55885598.

[44] Y. Yang, C. Shi and J. Li, "Of Benchmarking,” In: Proceedings of the International Conference on Information Engineering and Applications (IEA) 2012, Vol. 2, Springer, Berlin, 2013.

[45] D. M. Buede, "The Engineering Design of Systems: Models and Methods,” John Wiley \& Sons, Hoboken, 2011. 
[46] J. S. Gero and M. L. Maher, "Modeling Creativity and Knowledge-Based Creative Design,” Psychology Press, Hove, 2013.

[47] H. Meth, A. Maedche and M. Einoeder, "Exploring Design Principles of Task Elicitation Systems for Unrestricted Natural Language Documents,” In: Proceedings of the 4th ACM SIGCHI Symposium on Engineering Interactive Computing Systems, ACM, New York, 2012.

[48] S. Andradóttir, H. Ayhan and D. G. Down, "Design Principles for Flexible Systems," Production and Operations Management, Vol. 22, No. 5, 2013, pp. 1144-1156.

[49] Q. Cheng, C. M. Xiao, G. J. Zhang, P. H. Gu and L. G. Cai, “An Analytical Robust Design Optimization Metho- dology Based on Axiomatic Design Principles,” Quality and Reliability Engineering International, 2013, Early View.

[50] H. Z. Yang, J. F. Chen, N. Ma and D. Y. Wang, "Implementation of Knowledge-Based Engineering Methodology in Ship Structural Design,” Computer-Aided Design, Vol. 44, No. 3, 2012, pp. 196-202. http://dx.doi.org/10.1016/j.cad.2011.06.012

[51] Y. H. Wu and H. J. Shaw, "Document Based Knowledge Base Engineering Method for Ship Basic Design,” Ocean Engineering, Vol. 38, No. 13, 2011, pp. 1508-1521. http://dx.doi.org/10.1016/j.oceaneng.2011.07.014 